\title{
Os direitos humanos dos profissionais de enfermagem: proposta de novo referencial
}

The human rights of nursing professionals: proposal of a new referential

Los derechos humanos de los profesionales de enfermería: propuesta de nuevo referencial

\author{
Aline Albuquerque ${ }^{1}$ \\ Ivone Martini de Oliveira² \\ Orlene Veloso Dias $^{3}$
}

\begin{abstract}
Resumo
Objetivo: desenvolver aportes teóricos, baseados nos direitos humanos dos profissionais de saúde, aplicáveis aos profissionais de enfermagem. Metodologia: trata-se de estudo teórico e documental, cujo material de base para sua elaboração pode ser subdividido em fontes bibliográficas e documentais. Resultados: é possível aplicar o referencial teórico dos direitos humanos dos profissionais de saúde na ambiência profissional de modo a melhorar suas condições de trabalho e os cuidados em saúde. Conclusão: profissionais de enfermagem e outros profissionais de saúde não são formados para pensar em termos de direitos humanos, resultando no seu distanciamento da linguagem dos direitos humanos, não lhes permitindo se perceber como titulares de direitos humanos em face do Estado.

Palavras-chave: Direitos Humanos. Enfermagem. Saúde.
\end{abstract}

\begin{abstract}
Objective: to develop theoretical contributions based on the human rights of health professionals applicable to nursing professionals. Methodology: this is a theoretical and documentary study, thus, the basic material for its elaboration can be subdivided into bibliographical and documentary sources. Results: it is possible to apply the theoretical reference of the human rights of health professionals in the professional environment in order to improve their working conditions and health care. Conclusion: nursing professionals and other health professionals are not trained to think in terms of human rights, resulting in their distancing from the language of human rights, not allowing them to perceive themselves as holders of human rights vis-à-vis the State.

Keywords: Human rights. Nursing. Health.

\section{Resumen}

Objetivo: desarrollar aportes teóricos basados en los derechos humanos de los profesionales de salud aplicables a los profesionales de enfermería. Metodología: se trata de estudio teórico y documental, así, el material de base para su elaboración puede ser

\footnotetext{
${ }^{1}$ Professora de Bioética e Direitos Humanos do Programa de Pós-Graduação em Bioética da UnB. E-mail: alineaoliveira@hotmail.com.br

2 Enfermeira. Colaboradora do Conselho Federal de Enfermagem. Membro do Conselho Nacional de Saúde. E-mail: ivonemo@gmail.com

${ }^{3}$ Enfermeira. Professora da Universidade Estadual de Montes Claros. Membro da Câmara Técnica do Conselho Federal de Enfermagem. E-mail: orlenedias@yahoo.com.br
} 
subdividido en fuentes bibliográficas y documentales. Resultados: es posible aplicar el referencial teórico de los derechos humanos de los profesionales de la salud en el ambiente profesional para mejorar sus condiciones de trabajo y la atención sanitaria. Conclusión: profesionales de enfermería y otros profesionales de salud no están formados para pensar en términos de derechos humanos, resultando en su distanciamiento del lenguaje de los derechos humanos, no permitiendo percibir como titulares de derechos humanos frente al Estado.

Palabras clave: Derechos humanos. Enfermagem. Salud.

\section{Introdução}

A problemática em torno da violação dos direitos humanos dos profissionais de enfermagem é objeto de preocupação de entidades e organizações nacionais e internacionais, como do Conselho Federal de Enfermagem (Cofen), Conselho Internacional de Enfermeiros (CIE), da Organização Mundial da Saúde (OMS), da Organização PanAmericana de Saúde (Opas) e da Organização Internacional do Trabalho (OIT). Nesse sentido, a OMS considera, desde os anos 2000, a violência contra os profissionais de enfermagem no ambiente de trabalho uma epidemia mundial (1). Igualmente, estudos acadêmicos no Brasil e em outros países buscam identificar os principais fatores que impactam no cotidiano dos profissionais de saúde e que desencadeiam violações de seus direitos humanos. Os estudos de Toscano e Windal e Toscano e Weber, apontados por Campos e Pierantoni (2), revelam que os profissionais da saúde são aqueles mais vulneráveis às agressões, constituindo um quarto de toda a violência no trabalho. Com efeito, investigações expuseram que os profissionais de enfermagem são os que se encontram em maior situação de risco, quando cotejados com os demais profissionais de saúde. Identificaram que isso se dá em razão dos profissionais de enfermagem terem contato direto com os pacientes e os familiares, sendo alvo em situações de estresse, inclusive por parte de outros membros da equipe de saúde (3). O CIE (4) pontua que, na esfera dos profissionais de saúde, os profissionais de enfermagem apresentam risco particular, portanto há que se conferir prioridade à eliminação de todas as formas de abuso e violência contra essa categoria. De fato, Vieira (5) aponta que os profissionais de enfermagem "apresentam as maiores taxas como vítimas de violência física, psicológica, verbal ou sexual quando comparados aos demais profissionais de saúde".

No contexto brasileiro, é comum os profissionais de enfermagem sofrerem estresse em face da sua impotência diante de serviços de saúde que não atendem padrões mínimos de acessibilidade e qualidade. Há uma quantidade expressiva de profissionais de 
enfermagem que trabalha em condições precárias, com carga horária exaustiva, em que não há insumos em quantidade suficiente e laboratórios adequados, além de outros prérequisitos para cuidados em saúde com segurança e de qualidade.

No que tange aos estudos no país que tratam da violência contra profissionais de saúde, a maior parte foi realizada em unidades de emergência, hospitais gerais e na atenção primária. É importante registrar que, em sondagem realizada pelo Conselho Regional de Enfermagem de São Paulo (5), no ano de 2015, mais de três em cada quatro profissionais de enfermagem do estado de São Paulo relatam já ter sofrido algum tipo de violência durante o trabalho, sendo que a violência psicológica foi a mais citada $(81,54 \%)$, em seguida a violência física $(23,77 \%)$ e o assédio sexual $(10,68 \%)$.

Tramitam em Brasília, projetos de leis ( $P L)$ que, se aprovados, proporcionariam dignidade para os profissionais de enfermagem: o PL 2295/2000, que dispõe sobre a jornada de trabalho de 30 horas para enfermeiros, técnicos e auxiliares de enfermagem; o PL 459/2015, que estabelece piso salarial nacional os profissionais de enfermagem; e o PL 4998/2016, que normatiza a obrigatoriedade das instituições oferecerem locais dignos para a descanso desses profissionais. No entanto, o que se observa é que esses direitos não são prioridades para os políticos brasileiros, pois o PL da carga horária de 30 horas já tramita há quase duas décadas.

Constata-se que os profissionais de enfermagem constituem um grupo com vulnerabilidade acrescida e que seus direitos humanos, na ambiência profissional, se encontram suscetíveis a violações cotidianas. Por outro lado, a aplicação do referencial dos direitos humanos ao contexto dos cuidados em saúde e aos profissionais dessa área ainda se revela incipiente no Brasil. Cohen e Ezer (7) desenvolveram a aplicação dos direitos humanos ao contexto dos cuidados em saúde, por meio do referencial dos direitos humanos dos pacientes (DHP) e dos direitos humanos dos profissionais de saúde (DHPS); no Brasil, foi Albuquerque (8) quem levou à cabo a formulação teórica sobre tal referencial. Os DHP e os DHPS se caracterizam por uma proposta teórico-normativa inovadora e precursora, que abarca princípios e os direitos humanos dos pacientes e dos profissionais de saúde, conforme será exposto neste artigo. Albuquerque desenvolveu o referencial dos direitos humanos aplicado especificamente aos pacientes, os DHP, contudo, ainda não há no Brasil a sua formulação teórica na esfera dos profissionais de saúde. Assim, este artigo se mostra inédito ao abordar o contexto atual de violência e abusos sofridos pelos 
profissionais de enfermagem sob a ótica dos direitos humanos, particularmente de uma nova abordagem, os DHPS. Com efeito, compreender os abusos e violências contra profissionais de saúde à luz dos direitos humanos confere ao Estado a obrigação de enfrentamento dos contextos e ambiências que facilitam tais práticas. O referencial dos direitos humanos ocupa um espaço privilegiado no discurso público, debates políticos, políticas públicas e trazem em si valores que estão no ápice da aspiração humana (9). Embora tenha se optado por abordar particularmente os profissionais de enfermagem, a aplicação do referencial dos DHPS propugnada neste artigo também pode ser utilizada para todos os demais profissionais de saúde.

Tendo em conta a realidade vivenciada pelos profissionais de enfermagem, violadora de seus direitos humanos, este artigo tem como objetivo desenvolver aportes teóricos baseados nos DHPS aplicáveis a esses profissionais. O presente estudo consiste em pesquisa teórica e documental, assim, o material de base para sua elaboração pode ser subdividido em fontes bibliográficas e documentais. As fontes bibliográficas consistem, basicamente, em estudos teóricos acerca dos abusos e violência sofrida pelos profissionais de enfermagem, bem como na pesquisa formulada por Cohen, Ezer (7) e Albuquerque (8) acerca dos DHPS. Destacam-se, entre as fontes documentais, os documentos emanados do CIE, OMS, Opas, OIT e Cofen.

Por fim, sublinha-se o ineditismo deste estudo, considerando que são escassos os estudos, no Brasil, que empregam o referencial dos direitos humanos ao contexto profissional no setor saúde; em consequência, a temática acerca da violência e abusos contra profissionais de saúde em geral e de enfermagem é tratada a partir de outros campos do saber.

O presente artigo se encontra estruturado em quatro partes: a exposição da formulação dos referenciais dos DHP e dos DHPS; o reconhecimento institucional dos direitos humanos dos profissionais de enfermagem; os princípios da ADHCS aplicados aos profissionais; e, por fim, seus direitos.

\section{A abordagem de direitos humanos nos cuidados em saúde}

A abordagem teórico-normativa dos direitos humanos aplicada ao contexto dos cuidados em saúde se desdobra em dois referenciais: os DHP e os DHPS, os quais abarcam princípios e direitos humanos, estando esses últimos previstos em tratados e 
declarações internacionais. Os direitos humanos se originam de consensos ético-jurídicos construídos no âmbito da comunidade internacional e se encontram previstos em tratados e declarações, bem como assentam obrigações direcionadas, precipuamente, aos Estados, ou seja, estabelecem o que o ente estatal pode fazer, o que não pode fazer e o que deve fazer em relação às pessoas (9). Com efeito, cada um dos direitos humanos implicado nos cuidados em saúde, seja sob a perspectiva do paciente ou do familiar, se encontra previsto em documentos adotados no âmbito das organizações internacionais, tais como o Pacto Internacional sobre Direitos Civis e Políticos; o Pacto Internacional sobre Direitos Econômicos, Sociais e Culturais; a Convenção Europeia de Direitos Humanos; e a Convenção Americana sobre Direitos Humanos (8). Desse modo, à luz de tais normas, o referencial dos direitos humanos deve ser aplicado aos pacientes, constituindo-se os DHP, ou aos profissionais de saúde, que consiste nos DHPS, objeto deste artigo.

Os direitos humanos dos profissionais de saúde ensejam as obrigações estatais de respeitar, de proteger e de realizar. Assim, o Estado tem a obrigação de respeitar tais direitos, por exemplo, não estabelecer regras discriminatórias no tratamento de profissionais de saúde. Quanto à obrigação de proteger, tem-se a exigência direcionada ao Estado de que proteja os profissionais de saúde de violência e abusos perpetrados por terceiros. E, por fim, a obrigação de realizar implica a adoção de medidas legais, administrativas ou de outra natureza que propiciam a fruição dos direitos humanos dos profissionais de saúde (10).

Os DHPS reconhecem os profissionais de saúde como atores essenciais do cuidado, cujos direitos devem ser respeitados, tanto sob o argumento de que são titulares de direitos humanos, como de que a efetivação dos direitos dos pacientes se imbrica diretamente com tal respeito precipuamente por parte do Estado. Os profissionais não se encontram habilitados para prover cuidados em saúde com a qualidade adequada ao menos que seus direitos sejam respeitados e possam trabalhar em condições dignas, bem como com independência profissional. Cohen e Ezer (7) pontuam que, mesmo em sociedades democráticas, os profissionais de saúde se sujeitam, muitas vezes, a trabalhar em condições inseguras, são punidos por infrações éticas sem o devido processo legal ou são forçados a prover cuidados em saúde de baixa qualidade contrariamente aos seus princípios. Essas situações, além de violarem seus direitos humanos, apresentam riscos para os pacientes. Ademais, os abusos e violências contra os profissionais de saúde não 
são práticas isoladas, mas se inserem numa cultura de desrespeito aos direitos humanos, de uma forma geral, que coloca em risco de dano qualquer pessoa que tenha contato com o sistema de cuidados em saúde. Os DHPS não situam os pacientes em contrariedade aos profissionais de saúde, mas reconhece que a ênfase no papel do referencial dos direitos humanos nos cuidados em saúde endereça-se, notadamente, às questões estruturantes dos sistemas de cuidados em saúde e aponta para a responsabilização estatal (7).

Os DHPS compõem-se de princípios que proporcionam fundamentos para a interpretação e o processo de especificação (10) dos direitos humanos aplicáveis ao contexto dos cuidados em saúde, cujos titulares podem ser os pacientes ou os profissionais de saúde. Os DHP e os DHPS foram formulados como resposta ao discurso crescente sobre a necessidade de proteção dos direitos dos pacientes, violados de forma reiterada e grave no cenário das relações de cuidados, bem como dos profissionais de saúde (7). Desse modo, os DHPS partem do pressuposto de que a efetivação dos direitos humanos dos pacientes se entrelaça com a dos profissionais de saúde, na medida em que as condições de trabalho, a saúde física e mental, e o resguardo ao seu sigilo profissional repercutem nos direitos dos pacientes (8). No mesmo sentido, quando os profissionais de saúde são obstados de fruírem dos seus direitos, isso contribui para a mitigação do seu papel de promoção da autonomia e dos direitos humanos dos pacientes, bem como da prevenção de abusos (3). Em síntese, os DHP e os DHPS amparam-se na dignidade humana inerente e usam a linguagem e as normativas dos direitos humanos universais e legalmente reconhecidos a situações de cuidados em saúde, protegendo tanto os pacientes quanto os profissionais da saúde (7).

\section{O reconhecimento institucional dos direitos humanos dos profissionais de enfermagem}

Neste item, será abordada a temática dos direitos humanos dos profissionais de enfermagem sob a ótica de entidades e organizações internacionais e nacionais, que foram escolhidas em razão do seu papel desempenhado na esfera da saúde, como o caso da OMS e Opas; no âmbito da enfermagem, como o CIE, o Cofen e os conselhos regionais de enfermagem; e do trabalho, ao se tratar da OIT. Agregue-se o Royal College of Nursing $(\mathrm{RCN})$, entidade de enfermagem do Reino Unido, elegida em razão da sua atuação destacada na área dos direitos humanos e da enfermagem. 
O RCN produziu o documento precursor intitulado Human Rights and Nursing Position Statemen, no qual enunciou seu compromisso em apoiar o emprego do referencial dos direitos humanos a fim de que conduza a uma prática diferente e positiva para os pacientes, os profissionais da enfermagem e a sociedade (11). De acordo com o RCN, essa posição ampara-se em três pontos: a) há que se chamar atenção para o fato das violações de direitos humanos nos cuidados em saúde induzirem à alteração de conduta por parte dos profissionais de enfermagem; b) a prioridade do profissional e das equipes de enfermagem é o cuidado do paciente, e os direitos humanos podem ajudá-los a ofertar melhores cuidados em saúde; c) os direitos humanos previstos na Declaração Universal dos Direitos Humanos e nos tratados são a chave para a atuação da enfermagem e complementam os códigos de ética profissionais (11).

O CIE destaca o direito dos profissionais de enfermagem de praticar sua atividade profissional em um ambiente que salvaguarde sua segurança pessoal e impeça o abuso, a violência, a ameaça e a intimidação. É essencial que os profissionais de enfermagem compreendam os direitos humanos estatuídos nos tratados e declarações internacionais de forma a tomar consciência dos próprios direitos; bem como a importância da atuação política dos profissionais de enfermagem em advocacy, em prol do resguardo de seus direitos humanos por parte do Estado (12). Segundo o CIE, os profissionais de enfermagem, individual ou por meio de associações, têm o direito de contar com um canal de denúncia de violações de direitos humanos de pacientes, bem como com suporte e assistência para lidar com dificuldades relacionadas a situações de violação de direitos humanos de pacientes (13).

A OMS conta com a Política para Trabalhadores da Saúde e a Estratégia Global para os Recursos Humanos da Saúde (2017-2030). Nos princípios gerais da Estratégia, destaca-se o princípio acerca dos direitos de todos os trabalhadores em saúde, incluído ao ambiente seguro e digno de trabalho, e a liberdade de todas as formas de discriminação, coerção e violência (14).

A Opas formulou o Programa de Trabalhadores da Saúde (2015-2015) com a finalidade de promover a saúde dos trabalhadores e de ambientes de trabalho saudáveis, seguros e produtivos. O Plano de Ação sobre os Trabalhadores em Saúde fundamenta-se no marco conceitual da Opas, que versa sobre Saúde e Direitos Humanos (15). Consoante o Plano, os Estados devem promover e proteger os direitos dos trabalhadores, abarcando 
a perspectiva do direito à saúde e da Declaração da OIT relativa aos princípios e direitos fundamentais no trabalho, de 1998. O Objetivo 1.1 do Plano de Ação da Opas consiste no desenvolvimento e na atualização de instrumentos legais que monitoram a conformidade de políticas e padrões técnicos de vigilância e de controle das condições que afetam a saúde, o bem-estar e a vida dos trabalhadores, de acordo com os acordos internacionais da OIT e os instrumentos dos direitos humanos (15).

A OIT enunciou que apoia as iniciativas na direção da melhora das condições de trabalho e das relações laborais no setor saúde por meio de padrões laborais setoriais e do diálogo social, bem como colabora com a OMS com vistas a promover um ambiente de trabalho para os profissionais de saúde que seja acolhedor e saudável (16). A Convenção da OIT sobre Segurança e Saúde Ocupacional, de 1981, estabelece que os Estados devem formular, implementar e periodicamente rever política nacional sobre segurança e saúde ocupacional, bem como acerca do ambiente de trabalho. A Convenção da OIT sobre Serviços Ocupacionais de Saúde, de 1985, estatui a obrigação dos Estados de adotar provisões apropriadas para riscos específicos. A Convenção da OIT de Promoção da Segurança e Saúde Ocupacional, de 2006, versa sobre o dever de promoção de melhoras contínuas da segurança e na saúde ocupacional para prevenir danos, doenças e mortes ocupacionais (3). No contexto dessa atuação colaborativa, a OIT, a OMS e a Internacional de Serviços Públicos produziram as Diretrizes Marco para Enfrentar a Violência Laboral no Setor da Saúde (17). De acordo com as Diretrizes, cabe ao Estado, tornar a supressão da violência no trabalho do setor da saúde uma parte essencial das políticas e planos nacionais, regionais e locais de saúde, bem como a proteção dos direitos humanos (17).

Ainda, na esfera da OIT, destaca-se a Convenção da OIT sobre o Pessoal de Enfermagem, de 1977, que assenta o dever do Estado de adotar uma política endereçada aos serviços e aos profissionais de enfermagem. Quanto às condições laborais desses profissionais, a Convenção estabelece o dever dos Estados de implementar medidas direcionadas às condições de emprego e trabalho, considerando a perspectiva de crescimento na carreira e remuneração. A normatização estatal da matéria há que se ater para as horas de trabalho, incluindo a compensação de horas-extras; descanso semanal; licença maternidade e previdência social, dentre outros pontos relevantes para garantir os direitos humanos dos profissionais de enfermagem. Por fim, a Convenção aponta para a 
necessidade do Estado de tomar em conta a natureza especial do trabalho da enfermagem e o ambiente em que ele se dá (3).

$\mathrm{Na}$ esfera nacional, o Cofen, por meio do Código de Código de Ética dos Profissionais de Enfermagem, aprovado pela Resolução Cofen n 564/2017 (18), assentou que os profissionais de enfermagem têm direito à remuneração justa e a condições adequadas de trabalho, que possibilitem um cuidado profissional seguro e livre de dano. $O$ Cofen tem sistematicamente proposto e orientado o exercício da enfermagem fundamentado na ética e no respeito aos direitos humanos. A materialização disso foi o lançamento do Manual de Direitos Humanos para os Profissionais de Enfermagem, elaborado em parceria entre a Clínica de Direitos Humanos do Centro Universitário de Brasília (Uniceub) e o Cofen, no ano de 2017. Este manual tem como objetivos centrais promover a interação teórica e prática entre direitos humanos e a enfermagem, bem como oferecer aos profissionais aportes sobre direitos humanos aplicados à enfermagem, visando fomentar sua atuação como promotores privilegiados dos direitos humanos, qualificar a defesa dos direitos humanos dos profissionais da enfermagem e contribuir para que a relação com o paciente seja compreendida mediante o enfoque prioritário dos direitos humanos ao princípio da dignidade humana (19).

Os documentos expostos traduzem a preocupação de organizações e entidades internacionais e nacionais para com a vulnerabilidade acrescida dos profissionais de enfermagem, o que conduz a violações de seus direitos humanos. O contexto no qual tais profissionais desempenham suas funções apresentam fatores particulares que propiciam abusos e violações. Com efeito, a carga de trabalho excessiva; a expectativa de alta performance; múltiplos vínculos; baixa autonomia; deficiência de infraestrutura e escassez de insumos de saúde; e a redução de prestígio social (20) são fatores que impulsionam o contexto mencionado. O fato da enfermagem ter contato direto e diuturno com pacientes e familiares aumenta o risco de violência (2), em consequência, é obrigação do Estado, sob a ótica dos DHPS adotar medidas que previnam danos físicos e mentais aos profissionais de saúde.

\section{Os princípios do referencial dos DHPS}

A aplicação dos DHPS impõe a identificação de princípios que nortearão o uso da abordagem em políticas públicas, elaboração de normativas e resolução de casos concretos. Os princípios ora identificados foram extraídos da literatura especializada sobre 
a temática, mas são propostas originais das autoras deste artigo. Os princípios constituem padrões de conduta dos quais se inferem reclamos morais e julgamentos ético-jurídicos. Assim, um princípio é uma norma essencial em qualquer sistema moral e permite a especificação de normas que guiem a atuação prática (10).

Inicia-se com o Princípio da Não Discriminação do Profissional de Enfermagem, princípio central de qualquer abordagem baseada nos direitos humanos, que se aplica de modo transversal a todos os direitos humanos, distinguindo-se, assim, do direito a não ser discriminado. Consoante tal princípio, é vedada toda distinção, exclusão ou preferência fundada na raça, cor, sexo, religião, opinião política, ascendência nacional ou origem social, que tenha por efeito suprimir ou alterar a igualdade de oportunidade ou de tratamento em matéria de emprego ou profissão. Por exemplo, profissionais de enfermagem com deficiência não podem ser discriminados, notadamente quando se trata de salários ou outras condições de trabalho, assim, o Estado tem o dever de assegurar que a deficiência não seja um motivo, mesmo que oculto, para padrões de proteção trabalhista inferiores. No mesmo sentido, é importante ressaltar a vedação da discriminação baseada na opinião política (3).

O Princípio da Autonomia Funcional do Profissional de Enfermagem implica que as crenças e valores pessoais no exercício legal da profissão devem ser respeitados pelos gestores e provedores de serviço, bem como por pacientes. Desse modo, a liberdade de religião do profissional de enfermagem manifestada em seu ambiente laboral há que ser respeitada quando não coloque o paciente em risco de dano. Com efeito, o Princípio da Autonomia Funcional constitui-se pela autodeterminação do profissional que se expressa nos modos de execução do seu trabalho, nas escolhas técnicas e valorativas concernentes aos assuntos envolvidos no exercício da sua profissão e em outras formas de realização de cursos de vida profissional. Assim, "a autonomia profissional deve ser expressa no componente técnico do trabalho, demandando dos profissionais o controle sobre as intervenções e procedimentos técnicos que compõem suas atividades" (21). Tratando-se da enfermagem, o estudo de Melo aponta para as restrições da autonomia funcional da enfermeira no contexto do modelo bioético de cuidados em saúde, alicerçado no fato de que a sua margem de deliberação sobre os cuidados em saúde é extremamente limitada na medida em que se condiciona à aprovação médica, mesmo quando possui autorização legal para atuação (21). 
O Princípio da Dignidade nas Condições Laborais, o qual impõe que o Estado elimine as condições degradantes de trabalho, como a jornada excessiva, a falta de segurança e higiene, ou mesmo a alimentação inadequada. Desse modo, os profissionais de enfermagem têm direito a exercer suas funções em um ambiente livre de estresse e, quando as características da atividade impliquem riscos à saúde, têm o direito a ter acesso a serviços e medidas específicas que minimizem o risco laboral. Desse modo, o Estado tem o dever de proteger o profissional de enfermagem das condições de trabalho que possam causar danos à sua saúde e ao seu bem-estar. Assim, instrumentos legais devem estatuir a duração das horas de trabalho, o mínimo de descanso semanal e o pagamento de salários adequados. Quanto às profissionais mulheres, cabe ao ente estatal assegurar o direito à licença remunerada e a condições saudáveis de trabalho condizentes com o estado de gravidez (3). Nessa linha, o Código de Ética da Enfermagem (18) prevê o direito dos profissionais de "exercer atividades em locais de trabalho livre de riscos e danos e violências física e psicológica à saúde".

Os princípios dos DHPS são comandos ético-jurídicos que prescrevem condutas a serem adotadas pelos agentes estatais e empregadores dos profissionais de enfermagem.

\section{Os direitos constituintes do referencial dos DHPS}

O referencial dos DHPS é constituído por uma série de direitos humanos que se encontram previstos em tratados adotados pelo Estado brasileiro e aplicáveis aos profissionais de saúde, particularmente aos de enfermagem. Conforme o referencial dos DHPS, os direitos humanos são classificados em: direitos laborais; direitos pessoais; direitos profissionais e direitos humanitários.

Os direitos laborais abarcam os direitos humanos relacionados à condição de trabalhador e se desdobram nos seguintes direitos: a) direito a trabalhar em condições decentes, seguras e dignas, que são infringidos nas seguintes situações: sobrecarga de atividades, desvio de função e carência de recursos materiais e o uso de instrumentos obsoletos; b) direito ao lazer e à limitação razoável das horas de trabalho, cujas violações podem ser ilustradas como o cumprimento rigoroso e exaustivo, sem flexibilidade, de carga horária de trabalho e carga de trabalho excessiva; c) direito a uma remuneração justa e satisfatória, que não é observada quando o profissional de enfermagem recebe salário incompatível com a complexidade da função exercida ou defasado, acarretando em 
múltiplos vínculos; d) direito à liberdade de associação e assembleia, que pode ser desconsiderado quando o profissional de enfermagem é proibido de participar de sindicados e outras organizações para a promoção de seus interesses sem prévia autorização (3). O Código de Ética da Enfermagem estabelece que os profissionais têm o direito de apoiar e de participar de movimentos de defesa "da dignidade profissional, do exercício da cidadania e das reivindicações por melhores condições de assistência, trabalho e remuneração" (18).

Os direitos pessoais são aqueles direitos humanos relacionados à segurança pessoal, saúde e vida dos profissionais de enfermagem e abrangem os seguintes direitos: a) direito à vida e à segurança pessoal, que é desrespeitado quanto o profissional é vítima de agressões e violência física e moral; b) direito à saúde, o qual é violado quando há a ausência de medidas de prevenção de acidentes e doenças relacionadas ao trabalho, a carência de ambientes de descanso ou a privação do sono; c) direito a não ser submetido a tortura, nem tratamentos cruéis, desumanos ou degradantes, impondo o direito de não sofrer assédio moral, ser submetido a stress excessivo, e a condições de trabalho precárias (3).

Os direitos profissionais consistem nos direitos humanos relacionados ao desempenho do papel do profissional de enfermagem nos cuidados em saúde: a) direito à privacidade, implicando o respeito à objeção de consciência ou à recusa de procedimento. É quando o profissional de enfermagem é impedido de recusar a assistência por motivações de foro íntimo, ainda que não implique o dano ao paciente. O direito à privacidade engloba o direito à confidencialidade da informação pessoal do paciente dada ao profissional de enfermagem, ou seja, apenas nas hipóteses legais e sob determinadas condições, o profissional pode ser compelido a revelar tais informações (3). Também implica o direito do profissional de enfermagem de "negar-se a ser filmado, fotografado e exposto em mídias sociais durante o desempenho de suas atividades profissionais" (18); b) direito de não ser discriminado, que é inobservado quando o profissional de enfermagem é discriminado por qualquer fator pessoal, como gênero, raça, cor, etnia, orientação sexual, nacionalidade, credo e outros; c) direito de liberdade de expressão, como no caso do profissional não poder se manifestar sobre o cuidado em saúde de determinado paciente; d) direito ao devido processo legal e à ampla defesa, bem como ao remédio efetivo no caso do profissional de 
enfermagem ser processado judicial ou administrativamente por condutas desempenhadas no exercício da função, incluindo processos por infrações disciplinares (3).

O direito humanitário diz respeito à proteção do pessoal civil sanitário que se encontra em situação de conflito armado. De acordo com tal direito, o profissional de enfermagem que integra os serviços de saúde civis será respeitado e protegido e, se necessário, ser-lhe-á proporcionado toda a ajuda possível nas regiões em que esses serviços se encontrem desorganizados por razão da atividade bélica. Nos territórios ocupados, os profissionais serão auxiliados no que for necessário para que possam desempenhar sua missão humanitária da melhor forma e não poderão ser obrigados a realizar tarefas que não sejam compatíveis com sua missão. Ademais, os profissionais de enfermagem dos serviços de saúde civis terão acesso aos lugares onde seus serviços sejam indispensáveis, sem prejuízo das medidas de controle e segurança (20).

No Dia Mundial Humanitário, a OMS chamou atenção para a proteção a trabalhadores de saúde, bem como para os ataques contínuos a trabalhadores e instalações de saúde. Apenas em 2014, a OMS recebeu relatos de 372 ataques a profissionais de saúde em 32 países, e ações que resultaram em 603 mortes, deixando 958 feridos (22).

\section{Considerações finais}

No Brasil, não se introduziu a linguagem e a cultura dos direitos humanos nos cuidados em saúde, o que se reflete na ausência do referencial dos direitos humanos em políticas, programas e normativas da esfera dos cuidados em saúde. A ideia veiculada no Brasil de que todos se encontram no mesmo patamar de responsabilidade na esfera dos cuidados em saúde - gestores, trabalhadores da saúde e pacientes - minimiza a responsabilidade do Estado e mitiga a assunção de suas obrigações quanto aos direitos humanos.

Concluiu-se que o Estado é o responsável por assegurar condições dignas de trabalho dos profissionais de enfermagem e dos demais trabalhadores, bem como de assegurar o respeito aos seus direitos humanos. Profissionais de enfermagem e de outros profissionais de saúde não são formados para refletir e atuar sob a égide dos direitos humanos, resultando na manutenção do seu distanciamento dessa linguagem e não Ihes permitindo se perceber como titulares de direitos humanos em face do Estado. 


\section{Referências}

1. Conselho Regional de Enfermagem de São Paulo. Violência no Trabalho: guia de prevenção para os profissionais de Enfermagem. Disponível em: https://portal.corensp.gov.br/wp-content/uploads/2018/01/PDF-site-2.pdf [Acesso em: 20 out. 2018].

2. Campos AS, Pierantoni CR. Violência no trabalho em saúde: um tema para a cooperação internacional em recursos humanos para a saúde. Revista Electronica de Com. Inf. Inov. Saúde. Rio de Janeiro, 2010, 4(1):86-92.

3. Beletsky L, Ezer T, Overall J, Byrne I, Cohen J. Advancing human rights in patient care: the law in seven transitional countries. Disponivel em: https://www.opensocietyfoundations. org/sites/default/files/Advancing-Human-Rights-in-Patient-Care-20130516. pdf [Acesso em: 10 out. 2018].

4. International Council of Nurses. Abuse and violence against nursing personnel. Disponível em: https://static1.squarespace.com/static/579770cd197aea84455d6908/t/57 d86320d1758e16f4e0f202/1473798944490/C01_Abuse_Violence_Nsg_Personnel.pdf [Acesso em: 18 out. 2018].

5. Vieira GLC. Agressão física contra técnicos de enfermagem em hospitais psiquiátricos. Revista Brasileira de Saúde Ocupacional. Disponível em: http://www.scielo.br/pdf/rbso/v42 /2317-6369-rbso-42-e8.pdf [Acesso em: 20 out. 2018. p. 2.].

6. Conselho Regional de Enfermagem do Estado de São Paulo. SP cria grupo de combate à violência contra médicos e enfermeiros. Disponível em: https://portal.corensp.gov.br/noticias/sp-cria-grupo-de-combate-a-violencia-contra-medicos-e-enfermeiros/ [Acesso em: 20 out. 2018].

7. Cohen J, Ezer T. Human rights in patient care: a theoretical and practical framework. Health Hum Rights. 2013, 12;15(2):7-19.

8. Albuquerque A. Direitos Humanos dos Pacientes. Curitiba: Juruá, 2016.

9. Tarantola D, Gruskin S. Human Rights Approach to Public Health Policy. In: Grodin, Michael A, Tarantola D, Annas GJ, Gruskin S. Health and Human Rights in a Changing World. Nova lorque: Routledge, 2013. p. 43-57.

10. Beauchamp TL. Standing on Principles. Oxford: Oxford, 2010.

11. Royal College of Nursing. Human rights and nursing RCN position Statement.

Disponível em: https://www.rcn.org.uk/-/media/royal-college-of-nursing/documents/ publications/2012/may/pub-004249.pdf [Acesso em: 20 out. 2018].

12. McHale J, Gallagher A. Nursing and Human Rights. Londres: Butterworth Heinemann, 2003. 
13. International Council of Nurses. Nurses and human rights. Disponível em:

https://www.icn.ch/sites/default/files/inline-files/E10_Nurses_Human_Rights\%281\%29.pdf [Acesso em: 20 out. 2018].

14. World Health Organization. Global strategy on human resources for health: workforce 2030. Disponível em: http://apps.who.int/iris/bitstream/handle/10665/250368/97892 41511131-eng.pdf;jsessionid=31851B4F30A787E7B61DC00B389BA0F2? sequence $=1$ [Acesso em: 20 out. 2018].

15. Pan American Healht Organization. Plan of Action on Workers' Health. Disponível em: http://iris.paho.org/xmlui/bitstream/handle/123456789/33986/CD54_10Rev.1-eng.pdf? sequence $=1$ \&isAllowed=y [Acesso em: 20 out. 2018].

16. International Labour Organization. Health services sector. Disponível em: https://www.ilo.org/global/industries-and-sectors/health-services/lang--en/index.htm [Acesso em: 20 out. 2018].

17. OIT, OMS, ISP. Diretrices Marco para Afrontar la Violencia Laboral em el Sector de la Salud. Genebra, 2002.

18. Cofen. Resolução Cofen $n^{\circ}$ 564/2017. Disponível em:http://www.cofen.gov.br/ resolucao-cofen-no-5642017_59145.html [Acesso em: 20 out. 2018].

19. Uniceub. Cofen. Manual de Direitos Humanos para Enfermagem. Disponível em: http://biblioteca.cofen.gov.br/wp-content/uploads/2018/03/Manual-Direitos-HumanosEnfermagem.pdf [Acesso em: 20 out. 2018].

20. Dias EC. Condições de trabalho e saúde dos médicos: uma questão negligenciada e um desafio para a Associação Nacional de Medicina do Trabalho. Revista Brasileira de Medicina do Trabalho. 2015. 13(2): 60-8.

21. Melo CMM. Autonomia profissional da enfermeira: algumas reflexões. Escola Anna Nery. 2016; 20(4).

22. Protocolo Adicional às Convenções de Genebra de 12 de agosto de 1949 relativo à Proteção das Vítimas dos Conflitos Armados Internacionais. Disponível em: http://www.dhnet.org.br/direitos/sip/dih/prot1.htm [Acesso em: 20 out. 2018].

23. World Health Organization. Disponível em: http://www.who.int/emergencies/attacks-onhealth-care/en/ [Acesso em: 20 out. 2018].

Como citar esse artigo:

Albuquerque A, Oliveira IM, Dias OV. Os direitos humanos dos profissionais de enfermagem: proposta de novo referencial. Cadernos Ibero-Americanos de Direito Sanitário. 2019 jan./mar.; 8(1): 80-94. 